\title{
Participatory Budgeting in Local Authorities: Is E-governance the Missing Link? The Case of Harare City Council
}

\author{
Tawanda Zinyama \\ Department of Political and Administrative Studies \\ University of Zimbabwe \\ E-mail: zinyamat2010@gmail.comＭobile Number: +263 (04) 0773855061
}

Received: May 07, 2012 Accepted: June 10, 2012 DOI: 10.5296/jpag.v2i2.1988

\begin{abstract}
Harare City Council has both "processes" and "outputs" crises. The processes crisis includes waste, red tape, delay, mismanagement and corruption within the local authority. The outputs crisis involves failure to deliver what it should. Quality of service delivery is poor. E-governance contributes to poverty reduction through making communication easier and more affordable by enabling speedy and secure economic transactions. Participation is central to good governance and an important factor for sustainable development. Local authorities are closest to residents and thus in a better post to effectively drive participation. E-governance therefore means e-participation hence connecting residents of different social, academic, political and cultural backgrounds. The research explores the questions: how does e-governance improve service delivery and good governance such as responsiveness, transparency, accountability, effectiveness governance, improved participation, effectiveness and efficiency. The research findings indicate that the relationship between e-governance and participation is positive and strong. The findings are based on Harare City Council activities, analysis of key documents, views of key informant and content analysis. Recommendations proffered include the coming up with a shared e-governance strategy for Harare City Council by the Ministry of Local Government, Urban and Rural Development and Harare City Council. This must result in website creation. Residents' awareness must be conducted through workshops, seminars and conferences in order to explain the benefits of e-governance. Human development designed to empower residents with basic ICT skills must be embarked upon.
\end{abstract}

Keywords: Participation, e-governance, budgeting, transparency, efficiency, website, good governance 


\section{Introduction}

Participatory budgeting is a tool to increase democracy in local governance by permitting residents to participate in the formulation and spending of public budgets and in the making of important decisions regarding public life. Until today, such participation was made available mostly through physical meetings organised by public managers. The potential for e-governance in local authorities remains largely unexploited though Zimbabwe acknowledges the considerable benefits of information and communication technology (ICT) in promoting good governance. Even at national level, e-government is not yet comprehensively embraced as noted by Chief Secretary to the Office of the President and Cabinet, in his Keynote address at the E-Government Workshop when he said "It is the last pillar e-Government that had not been fully developed". In Harare City Council (HCC), which is the case study, the culture of democracy is not fully embraced, thousands of residents are not fully empowered to participate in the decision making processes of their local authority. This is because Harare City Council does not have a website. The chief purpose of this paper is to examine the effect of introducing e-governance in local authorities. It also seeks to build a framework that may increase residents' participation. This can be achieved through e-governance. The study investigated the views and perceptions of Harare City Council officials, employees, residents, Minister of Information and Communication Technology, Ministry of Local Government, Urban and Rural Development and residents associations on e-governance. The views were compared to what is in key documents. The recommendations are also offered.

\section{Historical Background of ICT in Zimbabwe}

The ICT progression can be traced back to 1972 with the institution of the Central Computing Services (CCSs), which was designed to provide ICT services to the public service. This was then followed with the espousal of the Integrated Results Based Management (IRBM) system in 2005. This system has the e-government as one of the three fundamental gears. With the inauguration of the Government of National Unity (GNU) under the Global Political Agreement (GPA), a fully fledged Ministry of Information Communication and Technology was established with the mandate of promoting the use of ICTs to augment national competiveness and socio-economic growth. The Government of National Unity drew up a Short Term Emergency Recovery Programme (STERP) in March 2009 and a 100-day Plan a month later. STERP recognises technology as "the critical engine for the transformation of Zimbabwe from a developing country to a modern industrial state (STERP, 2009:268). The Ministry of Information and Communication Technology committed itself to developing the country's national website increasing bandwidth to the internet gateway by 40 percent improving service delivery particularly in telephone and mobile communication services.

Zimbabwe has e-government development index ranking 0, 3230 based on the United Nations e-government criteria. The Modernisation Department in the Office of the President and Cabinet is responsible for taking the lead role in e-government planning and implementation. Zimbabwe held an all Stakeholder Consultative Workshop in August 2010 to chart a common shared way forward on e-government in the country. The workshop culminated in the production of an e-government Blueprint entitled "ZimConnect": 
E-Government Framework and Implementation Strategy (2011-2015). The blueprint document contains the following:

- An assessment of the current progress on e-government and the general status of information and communication technology(ICT);

- Strategies, incorporating the direction and focus of e-government;

- Programmes recommended for implementation;

- Key performance indicators (KPIs) and targets;

- Proposed e-government frameworks;

- Action plan and

- Implementation roadmap.

Essentially, this is designed to ensure apposite planning and sustainable implementation of e-government in Zimbabwe. To ensure implementation, a National ICT/E-Government Policy and Technical Advisory Committee to the Office of the President and Cabinet was constituted from among the stakeholders and meets every week to provide leadership and direction to the whole implementation process.

The Advisory Committee spearheads the following:

- Flagship applications;

- Management of top level National Internet Domains;

- E-government legal, regulatory and administration framework and the role of the regulator;

- Cyber security issues;

- Key players in e-government implementation and their roles;

- Provision of mobile public services; and

- Matters pertaining to a Data Center.

\section{Definitional Framework}

The World Bank defines governance as the exercise of political authority and the use of institutional resources to manage society's problems and affairs. Stoker (1998:38) views governance as "the action, manner or system of governing in which the boundary between organisations and the public and private sectors has become permeable.... The essence of governance is the interactive relationship between and within government and non-governmental forces". According to Stoker this implies joint action, a common purpose and value framework, as well as continuous interaction towards a shared agenda. In this perspective, good governance requires a democratic and engaged civil society that is able to ensure that neither the political nor the economic system is captured by elite interest groups and distorted to serve their needs. E-governance therefore means employing modern ICTs to address the issues of governance, i.e. the participation in the decision processes of citizens 
and other actors. This inter-alia implies deploying efforts in the participation of all citizens, the access-divide and promotes opportunities for social development (Kitaw, 2006:8). E-governance is the "use of ICTs to promote efficient and effective government, facilitate more accessible government services, allowing greater public access to information and making government more accountable to citizens" (Jensen, 2002). E-governance involves the delivery of government services and information to the public using electronic means. The United Nations Educational, Scientific and Cultural Organisation provides an elaborate definition (UNESCO, 2005):

“.....the public sector's use of information and communication technologies with the aim of improving information and service delivery, encouraging citizen participation in the decision making process and making government more accountable, transparent and effective".

According to Chisenga (2004), e-governance is meant to fulfil the following goals:

- Improve the internal organisational processes of governments

- Provide better information and service delivery

- Increase government transparency in order to reduce corruption

- Reinforce political credibility and accountability

- Promote democratic practices through public participation and consultation.

A study conducted by Chisenga (2004) noted that the majority of the African governments are finding their way into Cyberspace through the construction of their own websites. Websites are essential tools for governments to realise effective e-governance. E-governance promotes and improves the democratic discourse, government and business of governance.

According to Sangonet (in Chisenga 2004) the following benefits can be realised if governments distribute their information through ICT tools such as the internet and the web:

- It costs less than print distribution

- Broad distribution can be achieved at relatively little cost

- Speedy distribution is possible at low cost

- More information can be made accessible at lower costs

- Different types of information can be distributed (staff, members of departments, contact details)

- People can respond or put views across

- It puts into effect commitment to transparency, accountability and democratisation.

Commenting on the benefits of e-governance in China, Kluver (2005:76) argues that:

"e-governance initiatives in China have had as their purpose not the empowerment of citizens, nor even to attract external investment, but rather to add stability or order to a chaotic governing process and social change and to re-establish the control of the governing authorities, including improving the quality of surveillance and data gathering and hence 
policy making, the elimination of corruption and ultimately the re-legitimation of the Communist Party of China"

The extant literature highlights the great potential of ICT tools for operational efficiency, cost reduction quality of services, convenience, innovation and learning in public sector. Osborne and Gaebler (1992) referred to citizens as customers for governments, since government need to empower rather than serve, to shift from hierarchy to teamwork and participation, to be mission oriented and customer focused, and to focus on prevention rather than cure. Governments worldwide are faced with the challenge of transformation and the need to modernise administrative practices and management systems (Tapscott, 1996). E-governance is the instrument for transforming and modernising administrative systems.

\section{Methods and Procedures}

The methods used to collect the data for analysis included the following:

- A desk review of relevant Zimbabwean documents on ICT

- Local authorities e-governance material

- Semi-structured interviews

- Participant observation

\section{Results and Discussions}

The HCC published a schedule of the budget consultation meetings in the Sunday Mail of 21 to 27 of 2011. The schedule clearly indicated the name of the ward councillor or councillor responsible for facilitating a meeting, date, time, venue and the respective ward in which the meeting was to be held. In total thirty-four (34) pre-budget consultation meetings were supposed to be held in the communities. From the published schedule, some of the wards were paired for example wards 3 \& 4 (Mbare); 11 \& 12 (Mbare National); 25 \& 26 (Highfield); $39 \& 40$ (Dzivarasekwa). The pairing of wards brought confusion to the residents who intended to attend the meetings. HCC like in previous years used the Sunday Mail to publicise the meetings. To most vulnerable and poverty stricken residents in the communities, the newspaper remains rare and unaffordable commodity to them. Buying a newspaper is viewed as a luxury by the resident who is failing to pay his/her rates to council especially in high density areas ${ }^{1}$. This schedule of meetings was not well published. There were several changes and shifts to the initially published schedules for example in Greendale, Mandara, Waterfalls, Mabvuku and Tafara. This gave confusion to the residents as they would reach venues where there was not even a single council official. A total of fifteen meetings, were held as scheduled out of the publicised thirty-four (34). Eight other meetings were held after they had been postponed. Percentage wise, there was $44 \%$ adherence to the published schedule. Several meetings were cancelled due to poor planning and poor attendance. There are forty-six (46) wards in Harare, but the HCC plan did not cover some of the wards. This can be exemplified by Borrowdale ward 18; Southerton ward 14, Highlands's ward 8 and Budiriro ward 37. There is need to strictly adhere to the published schedule. Changes to the initial schedule should be widely published so as to reduce confusion in the process. 


\section{Mll Macrothink}

Journal of Public Administration and Governance

ISSN 2161-7104

2012, Vol. 2, No. 2

The HCC produced publicity flyers for the pre-budget meetings in the communities. The flyers were given to elected councillors responsible for meetings in the area. The clear number of flyers given to each councillor is not known. The flyers are said to have been dropped door to door and in the residents' letter boxes as invitation to the residents of a particular ward. The Public Relations department of the HCC is either totally dysfunctional or it dismally failed to recognise publicity opportunities for the HCC when they see them. The Harare Residents Trust produced at least 360 invitations to mobilise people to attend the meetings. The publicity flyers were not in vernacular language but were in English. Most illiterate residents failed to find the need and importance of attending the meetings. Publicity of meetings was a challenge for councillors representing low and medium density areas. Citizens have lost interest in public affairs. Examples in which meetings were well published was in Harare central, Avenues areas where the councillor Charles Nyatsuro ward 2 and ward 6 dropped flyers in many residential flats but residents never showed up for the meetings.

Residents in the targeted communities failed to attend most of the meetings. Of the 23 meetings held, only six had over hundred (100) people. The attendance at most meetings was very poor leading to cancellations. Overall attendance at the HCC pre-budget consultative meetings was extremely pitiable. This could be an indicator of no confidence in the local authority or people are fed up with seemingly political gatherings that do not bring tangible benefits. It could be that the councillors are unknown or they are too partisan to want to address audiences that they do not control or know. In separate discussions on this, some residents said their voice was not being taken seriously so they found no reason to participate in the meetings. The study notes that during budget process, when objecting, residents are expected to write what they object about the budget, indicate their addresses and submit the letter to the Town Clerk at Town House within the allocated time of thirty (30) days from the day the first advertisement in the media. In terms of section 219 (3) of the Urban Councils Act Chapter 29;15 (a) if a statement has been advertised and objections are raised by more than thirty (30) voters or users of the services to which the tariff, charge or deposit relates on (b) where there are less than 30 such users of the services concerned by not less than fifty percent $(50 \%)$ of the number of such users, such tariffs, charges or deposits shall not come into operation unless the resolution is again passed by a majority of the total membership. This therefore implies that very few residents can walk or visit the Town House to drop the objections. This undermines effective participatory budgeting. E-governance is the panacea for this challenge.

E-governance requires Harare City Council in this case to set up a website that most information such as council meetings full council meetings, help lines and action plans can be easily accessed. In the context of participatory budgeting it means that the budget advertised in the newspapers will also be posted on the website and comments would come via e-mail plus traditional post and representations at meetings. Therefore e-governance improves PB practices. The Harare residents may comment on the budget proposals over the internet, use of cellphone SMS and maintenance of the local area network and wide area network have to be considered by HCC. This is the critical area where HCC is found wanting. According to Chaeruka and Sigauke (2007:11) note that "PB works well where there is a free 
flow of and easy access to information". They further argue that e-governance system/platform though is expensive to establish but is very useful where the community hooks on to it (ibid). This is in tandem with Zwizwai, 2007 who noted that "empowers people and provides them with the opportunity to make their own informed choices as to what works best for them in their particular environment".

The content of the discussions at the meetings defeated the whole purpose of budget consultative meetings. There was never meaningful debate on the HCC 2012 budget. Meetings were reduced to mere service delivery meetings and residents were exploited to get them to ask important questions to their communities. There has not been adequate feedback on council's operations hence the criticism that they have not been effectively represented by their elected councillors.

All residents need the HCC to prioritise water supplies to the communities by pumping adequate and clean water to the communities, consistent refuse collection and audited financial statements for previous budgets before a fresh budget can be crafted. This is a clear indication that residents of Harare have lost confidence in council systems and feel that their rates are being diverted to foot management expenses for luxurious life styles at the expense of service delivery. There is increased conflict between residents and the local authority which is bound to affect revenue collection.

The researcher monitored the pre-budget consultation meetings by the City of Harare in the communities. The study observes that the pre-budget meetings were disorganised, shambolic, muddled, there was less adherence to the initially published schedule, the content of the meetings did not discuss in depth the budget of HCC, councillors botched to lead discussions according to residents' expectations, cancellation of meetings due to poor attendance, only three meetings had the participation of over 100 people. This undermined the quality of discussions and residents participation. Although the City of Harare was well represented at the meetings with employees from various council service departments such as the Housing and Community services, Urban Planning Services, Town House, City Treasury, Public Works and Waste management, HCC officials failed to outline the real objective or the idea behind the meetings. Councillors and City of Harare teams identified the key objective of the meetings as a platform for residents to say out what they want in the budget which will then determine the capital budget and ultimately the cost of council services. Harare Residents Trust official said that "the problem starts from what was identified as the key objective as it shows that residents had and have little to play in determining the cost of services they will eventually pay for" ${ }^{\prime 2}$. There has been a total lack of transparency in the manner in which the City of Harare has handled the budgets from 2008 up to now. There has been as serious lack of transparency and accountability by the City of Harare on budgets. Council officials concentrated on mentioning their assumed successes such as resurfacing Borrowdale road and acquiring 20 refuse trucks and replacement of water pipes in the CBD just to mention a few. The meetings were reduced to pure service delivery meetings rather than budget formulation meetings. The council has ceased to be a public institution where expenditures are supposed to be known to the rate payers. 
If HCC, implements e-governance, it would offer residents a choice of channels and means for interaction with the residents including internet-based information and services. The HCC must create a services website so that information can be easily updated and new services added. This would be in line with the sentiments at national level as stated by President Mugabe when launching e-government on 2 August 2011 and he said "Through implementation of the programme, Government will be able to provide online services conveniently through the use of ICTs, bring government services to closer the people, improve communication between government and citizens, reduce government operating experiences and be more transparent and accountable in the manner we provide services" 3 . The residents would be in a position to communicate with the council online as regards the efficiency and effectiveness of services. HCC must recognise that e-governance strengthens the residents-city council engagement through publishing HCC information online and inviting input, comments and feedback speedily ${ }^{4}$.

The interviews conducted with the Mayor, Town Clerk, IT Director, City Treasurer and Chamber Secretary disclosed that the city fathers do not appreciate the benefits of e-governance. The reason given by the mayor as to why the City does not have a website or e-governance was that "there are very low levels of ICT access amongst the majority of the residents, except for mobile communications using SMS messaging and 'Please call me"'. The study observed that low penetration levels of ICTs and the lack of affordability of using mobile phones and the internet is in rural areas not urban areas like Harare. In Harare almost every adult person has a "Facebook" account. This implies that they have e-mails hence indicating high ICT penetration levels. Fine, if the residents do not have requisite skills to use basic ICT tools and devices must be capacitated through training. Startlingly, the Town Clerk in formed the study that in 2004 the council formulated a "Turnaround Strategy" whose purpose is to achieve a 'World Class City' status by 2015. The strategy seeks for the creation of a clean, safe and secure city with reliable service delivery. "It is about team leadership, ability to know what our ratepayers presently need and the anticipated needs together with the ability to communicate through our vision" "The question is how can the residents' needs be known to HCC without e-governance?

Residential survey results show that approximately ninety percent $(90 \%)$ of households in Harare have access to a mobile phone and fifty-two percent (52\%) households have access to landlines. These statistics only cover the high densities. The medium and low density areas have hundred percent (100\%) access to ICT facilities. This calls for HCC to design highly specific access and delivery strategies for e-governance, connectivity and digital inclusion. The study discovered that a substantial number of households have the potential to retrieve information from or about Harare City Council through the internet using either personal computers(PCs) via fixed line connections or mobile phones. In Zimbabwe, internet access has tremendously grown. Of course, the cost of PCs, high cost of dial-up access charges and line rentals may be obstacles. Using mobile phone technology to access the internet is within the reach of almost residents. The Table 1 shows households access to internet facilities. 
Table1: Households Access to Internet Facilities

\begin{tabular}{|l|l|l|}
\hline ICT Access & Yes & No \\
\hline Cellphone & $99.9 \%$ & $0.01 \%$ \\
\hline Internet Facilities & $17 \%$ & $83 \%$ \\
\hline Landline & $38 \%$ & $62 \%$ \\
\hline Radio & $72 \%$ & $28 \%$ \\
\hline Television & $96 \%$ & $4 \%$ \\
\hline
\end{tabular}

The basic ICT statistic, while providing limited insight into community level of ICT penetration, do suggest that the successful application of e-governance as far as e-services is concerned would need to be based on the realities of high levels of internet access and high levels of mobile voice and data access. 99, $9 \%$ of Cellphone possession shows that the SMS must be extensively used by HCC in account payment notification and balance enquiry of amount due to city council. Gleaned from this is that residents can communicate with HCC online as regards efficiency and effectiveness. E-governance therefore strengthens residents-HCC engagement through publishing HCC information on line and inviting input, comment and feedback. These calls for HCC to create a menu of e-governance interactions that will be valued by residents.

HCC must come up with a strategy which must aim to provide broadband access to all households, business and institutions in Harare province. The study was shocked to discover that HCC big as it is, does not have the idea project even at the conceptual or planning phases for introducing e-governance. That's very sad. Harare City Council does not have a dedicated e-governance unit or division. This indicates lack of strategic, visionary and good governance oriented leadership.

Introducing e-governance is "a costly and risky exercise, and risk is increased by working in isolation" (Abrahams and Newton, 2008:3). Vendor lobbying, lack of thorough feasibility studies resulting in white elephants, poor contract management, low levels of staff capacity to use ICTs, a focus on tools rather than systems and poor take-up rate by end users due to inadequate computer literacy or affordability access were given by Abraham and Newton (2008) as reasons why e-governance has not taken root or flourished in most local governments in Africa. This suggests that HCC must give greater attention to building strategic vision and responsiveness of e-governance projects. This would in the long-run increase HCC's responsiveness to the real needs of residents, business and residents associations. For this to happen, there should be alignment between the technology medium for providing e-services and the method of communication access by users, For instance, the supply of information via website relies on people having easy and affordable internet access, while providing services via toll-free numbers. This has implications for e-governance as the 
channels available to facilitate interaction between residents and HCC depend heavily on the penetration of affordable ICT services. The study observed that that most residents rely on mobile technology for communication and interaction. It is beyond an average resident's affordability to contact HCC via mobile phones and most people use their phones for text messages including the free "Please call me" service. Therefore, residents cannot interact with HCC in an affordable and convenient way due to a broad policy failure to achieve universal service and access in the council. The major challenge is the design of an e-governance policy framework that applies to local government collectively, detailing the actions required from each sphere of local authority. HCC actually needs e-governance system to reduce information poverty and foster time-saving and convenience for residents.

The key informant interviews with residents' association leaders and selected business directors and managers revealed that e-governance is a necessity not a luxury. The informants converged on the following benefits of e-governance: promotion of residents' empowerment, service delivery improvement, strengthening accountability, increased transparency and improving council efficiency. The business community feels that e-governance will lower their costs, reduce red tape and simplify regulatory processes thereby assisting businesses to be more competitive. Putting services online substantially decreases the processing costs of many activities compared with the manual way of handling operations. This reflects that once HCC creates a website, through internet, HCC can deliver to all residents improved services, reliable information and greater knowledge in order to facilitate access to the governing process and encourage deeper residents' participation. The study found that e-governance allows HCC to talk, listen, relate and continuously communicate with its residents, therefore supporting accountability, democracy and improvements in service delivery. E-governance permits residents access to HCC information and services instantly, conveniently, from everywhere, by use of multiple channels such as PC, web TV, mobile phone or wireless device. It enables and reinforces their participation in local community life, for example, by sending an e-mail or contributing to an online discussion forum. This concurs with the observation made by Crede and Mansell, 1998 when they said: "ICTs offer the potential not just to collect, store, process and diffuse enormous quantities of information at minimal cost, but also to network, interact and communicate across the world".

The Minister of Information and Communication Technology, Honourable Nelson Chamisa, informed this study that e-governance is needed to deal with "lack of transparency, accountability and anticorruption". According to him "ICT is the economy and the economy is ICT". E-governance helps to increase the transparency of budget formulation and decision making processes. He further said that e-governance gives residents the opportunity to directly participate in decision making, by allowing them to provide their own ideas and suggestions in forums and online communities. If web sites are designed carefully and openly, they can be valuable resources for transparency as residents, businesses and other stakeholders should be able to see political and council information, bylaws and policies. The Minister Chamisa thinks that HCC must create a website with the objective of reducing corruption and increasing transparency by sharing a large amount of information related to corruption with residents, councillors and senior management at HCC. The residents must be highly encouraged to make their complaints and to provide information against council 
authorities who fraught rules and procedures. The Minister sees the following as challenges facing ICT development in Zimbabwe:

- "Inadequate resources in government affect our projects and aspirations;

- The Ministry often suffers from the aliment of unprofitable conflict, attacks and undermining;

- There is mistrust and in some cases failure to appreciate the positive role of ICTs can play in national development and the building of a World-class economy; and

- New ideas are taken as dangerous bullets that have to be deflected and shielded"6

Responding to the question: Why do you think there is this antagonism in the inclusive Government?, he had this to say

"It is because of lack of appreciation of ICT. There is a disease of securo-phobia mutating into technophobia. Some think that ICTs can expose their corruption and their lack of professionalism. ICT is the best police. It reports exactly what it records, which is good for fighting corruption", .

The observations by the Minister explain why even the HCC does not have conceptual framework on e-governance. An astute leader of Harare Residents Trust, one of the respondents, noted: "Harare City Council must focus on modernising council systems and processes through the use of information and communication technology. ICT would enhance the council's ability to provide services to its residents and stakeholders in an efficient and effective manner" ${ }^{\prime}$. This implies that by embracing e-governance, HCC will extraordinarily improve its operational efficiency. Furthermore, e-governance allows residents to send their questions, comments and suggestions for further improvement ${ }^{9}$. This feedback mechanism is very critical for Harare City Council for decision making. One academic noted that "the major e-governance challenges are lack of leadership in terms of motivate, involve, influence and support; lack of change management strategy (culture and resistance to change), and policy framework, i.e. legislation" 10 . The study notes that in addition to the above challenges, information and communication technology infrastructure in dimensions such as e-readiness, computer literacy and telecommunication equipment must be also considered. The literacy is not an issue in Zimbabwe, in particular Harare residents. Zimbabwe has a higher level of human development hence the more likely Harare residents will be inclined to accept and use e-governance applications. One respondent observed that "the policy framework in terms of rules, policies, laws and legislative changes to address electronic activities including electronic signatures, electronic archiving, data protection and computer crime"11. E-governance laws are not yet formulated by Harare City Council neither by the Ministry of Local Government, Urban and Rural Development. This shows that leadership deficit as a driving force of every new and innovative project. Leadership is crucial before, during and after e-governance programme implementation. One respondent strenuously explained that "leadership is needed to manage change and support the programme, overcoming the organisation's natural resistance to change and marshalling the resources needed to improve management"12. 
Eighty percent of the total respondents are of the view that e-governance may enhance local revenue generation. The Harare City Council has the challenge of maximising society's contribution to the HCC's development with minimal efforts and resources. Innovative measures and radical changes have to be made to ensure effective monitoring of revenue for the good of the community. "The need to correctly and efficiently assess, record and monitor and collect fees, charges are necessary"13. Responding to the question: what role does internet play in local government?, the following were aired by academic at the University of Zimbabwe:

- "to provide information about the face-to-face participatory budgeting, for example, HCC uses internet to explain how the PB works, give information about PB meetings;

- Providing information about PB deliberations, implementation, e.g. information for basic PB development and monitoring to help people follow the schedules; and

- Residents are able to vote for their priorities online"13.

\section{Conclusions and Recommendations}

The findings from documentary search, key-informant interviews, participant observation, e-mail and telephone interviews have demonstrated that e-governance is indeed the missing connection in Harare City Council. This was shown by the shambolic nature of the participatory budgeting. Transparency of Harare City Council including residents' participation in decision making is dreadfully restricted. Good governance ensures that political, social and economic priorities are based on broad consensus in society and that the voices of the poorest and the most susceptible are heard in decision making over the allocation of development resources. Therefore, it can be gleaned from the findings that e-governance increases the efficiency of HCC operations in terms of information and communication flow across its departments, strengthening democracy through residents participation in decision making and enhancing transparency as well as accountability by publishing HCC information and providing better services to residents and business. E-governance plays a critical role in coordinating the actions of a large number of interested stakeholders. It presents the potential for HCC to recast its activities and processes, building relationships between residents and the council. This definitely enhances transparency, increasing HCC's capacity and providing a voice for those outside council. In a nutshell, the study realised that e-governance is the use of information and communication technology to improve service delivery provision activities within local authorities and the general populace. Through the internet HCC will be in a position reach wide audiences and thousands of people can deliberate over budget allocation. Kitaw (2006:14) summarised the tangible opportunities offered by e-governance initiatives:

- Transformation of cumbersome public administration and service delivery processes thereby increase efficiency of governments;

- Empowerment and participation of citizens, thereby contribute to strengthening democratic processes;

- Greater transparency and accountability, thereby lead to better governance and reduce 
opportunities for corruption; and

- Stimulation of the usage of ICT applications in other development sectors (e-health, e-education) thereby opens opportunities to transform agriculture-based economies

\section{Recommendations}

The main recommendation is that the Ministry of Local Government, Urban and Rural Development and the Harare City Council should come up with a shared strategy that places the purpose of e-governance in local authorities as being social and economic development. Both the Ministry and HCC lack a strategic vision with regard to e-governance in local authorities as indicated by the absences of a single document outlining the purpose and objectives of e-governance. E-governance can stimulate priority projects that place new technologies at the service of large segments of the residents in ways that would have a significant impact on the lives of the Harare residents. Thus e-governance creates social and information capital to the poor residents.

Other recommendations are:

- Situation analysis: a comprehensive study to assess national and local frameworks for e-governance to obtain and understand enabling and disabling factors must be instituted before the HCC bank rolls out the e-governance project.

- E-readiness evaluation: Harare City Council must commence with an e-readiness appraisal study to enable all stakeholders to comprehend the state of legal and regulatory framework. If the study is done is done competently and professionally, HCC would be able to come up with strategies and action plans for building legislative frameworks, institutional infrastructures, technological infrastructures and accessibility for all residents in a customized and successful manner.

- Residents' awareness: This must be done through workshops, seminars and conferences with the aim of raising awareness about real opportunities and benefits that the ICT revolution can bring. This way residents will be able to participate during the budget process.

- Capability to function: massive investment in human development is necessary for the staff to be able to handle new processes and activities. Some basic training needs are necessary to be provided to residents in order for them to be able to use new ICT facilities for accessing electronic information and services.

- Sensitivity analysis: HCC should demonstrate sensitivity to local realities by assessing and evaluating different alternatives and solutions for digital governance development including mobile telephones, kiosks and multi-channel access to services. This will ensure effective participation of the community in the information economy. HCC must establish knowledge management processes and tools to ensure storage, usage, easy retrieval of strategic information and knowledge for better and fast decision making process, for further adaption and development. 


\section{Endnotes}

1. Interview with a civic leader

2. Interview with Harare Residents Trust official

3. ZTV news at 2000 hours on 2 August 2011

4. Interview with a Member of Parliament

5. Interview with Mayor of Harare City Council

6. Interview with Minister of Information and Communication Technology

7. Interview with Minister of Information and Communication Technology

8. Interview with Harare Residents Trust official

9. Interview with an academic at the University of Zimbabwe

10. Interview with respondent

11. Interview with Member of Parliament

12. Interview with Civic leader

13. Interview with Ministry of Local Government, Urban and Rural Development official

14. Interview with the City of Harare Town Clerk

\section{Bibliography}

Abrahams, L and Newton R.L (2008) E-governance for Social and Local Economic Development: Gauteng City Region Perspective, Link Public Policy Paper No.9 November 2008.

Chaeruka,J. and Sigauke,P. (2007) Practitioners' Reflections on Participatory Budgeting in Harare, Mutoko and Marondera Workshops/Meetings and Experiences, in Making Participatory Budgeting Work in Africa, Local Governance and Development Journal, Volume 1. Numbwer2, December 2007.

Chisenga, J. (2004) Africa Governments in Cyberspace: Are They Bridging the Continent Divide? In Birungi, P. and Musoke, M.G., SCECSAL XVI, Towards a Knowledge Society for Africa.

City of Harare (2004) Turnaround Strategy, Harare, October 2006.

Coleman, S. (2005) African e-Governance-Opportunities and Challenges, Oxford Internet Institute, University of Oxford, UK.

Fang, Z. (2002) E-Government in Digital Era: Concept, Practice and Development, International Journal of the Computer, Volume, 10 (2): 1-22.

Heeks, R (2003) Most eGovernment-for-Development Projects Fail: How Can Risks be Reduced?, iGovernment Working Paper Series, IDPM, University of Manchester, UK. 


\section{Macrothink}

Journal of Public Administration and Governance ISSN 2161-7104 2012, Vol. 2, No. 2

Jensen, M (2002) Information and Communication Technologies as Tools for Improving Local Governance in Africa: A UNESCO Project Mission report and Assessment of the Current situation and outlook in selected African Municipalities (Zanzibar, Lusaka and Maputo) to identify needs for training on e-governance.

Kluver, R. (2005) The Architecture of Control: A Chinese Strategy for E-governance. Journal of Public Policy 25(1): 75-97.

Kumar, A. and Bhatnagar, S. (2001) VOICE: Online Delivery of Municipal Services in Vijaywada, India, World Bank.

OECD (2001) Engaging Citizens in Policy-Making: Information, Consultation and Policy Participation, Puma Policy Brief No.10.

McClure, D.L. (2001) Electronic Government: Challenges Must Be Addressed with Effective Leadership and Management. GAO-01-959T, Testimony before the Senate Committee on Governmental Affairs, on behalf of the U.S General Accounting Office.

Rose, R. (2005) Introduction: The Internet and Governance in a Global Context. Journal of Public Policy, 25 (1):1-3.

Stoker, G. (1998) Public-Private Partnerships and Urban Governance, in: Pierre, J. (ed.), and Partnerships in Urban Governance: European and American Experience, Macmillan, Basingstoke, pp 34-51.

United Nations Educational, Scientific and Cultural Organisation (UNESCO) 2005: E-governance Capacity Building.

United Nations Development Programme (2006), "Governance for Sustainable Human Development: A policy Document, Washington D.C.

United Nations ICT Task Force (2005), Information and Communication Technologies and the Millennium Development Goals, New York: UN ICT Task Force.

Zwizwai, B.M.(2007) 'Information and Communication Technology, Gender and Human Development', thematic paper for the Zimbabwe Human Development Report, 2007, Harare: UNDP.

\section{Internet sources}

http://docs.google.com/viewer?a=v\&q=cache Accessed on 13 April 2012

http://www.dissanet.com accessed on 16 April 2012

http://portal.unesco.org/ci/en Accessed on 16 April 2012

http://www.zimtreasury.org./download/pdf accessed on 08 Ma 2012

\section{Newspapers}

The Herald, 3 August 2011: Zimbabwe: President Launches E-Government.

Zimbabwe Independent, Thursday, 05 January 2012: Zimbabwe Should be Digital by 2015:Elias Mambo 